\title{
Coronavirus: un desafío global
}

\section{Coronavirus: a global challenge}

\author{
María Teresa Valenzuela'
}

Palabras clave: SARS-CoV2; salud pública; pandemia; diagnóstico; vigilancia epidemiológica

Nos encontramos viviendo la mayor crisis global en salud pública en décadas, con impactos políticos, sociales y económicos, debido a la dispersión por el mundo de un nuevo agente viral. Ningún país de este planeta está inmune a un virus que tiene potencial epidémico, dada la alta tasa de transmisibilidad de humano a humano. Toda la población es susceptible porque se trata de una nueva cepa, por la facilidad de contagiar por el mero hecho de la cercanía entre los individuos susceptibles, incluso sin contacto físico y por la gran movilidad de los individuos contagiados.

La globalización explica en parte la aparición de nuevas enfermedades emergentes, causadas por agentes infecciosos recientemente identificados y anteriormente desconocidos, capaces de causar problemas de salud pública a nivel local, regional o mundial. Ejemplos de éstas son el Síndrome Respiratorio Agudo Severo (SARS), Síndrome Respiratorio del Medio Oriente (MERS) y H1N1. SARS y MERS son epidemias causadas por coronavirus.

Otras importantes razones de la aparición de estas enfermedades son la deforestación y consumo de alimentos infectados, que debido al importante crecimiento de libre mercado y la falta de regulación sanitaria adecuada permite en algunos países la venta de carnes de animales semisalvajes infectados que generan infecciones, como Escherichia coli entero hemorrágico causante de enfermedades vasculares y renales severas o por Vibrio cholerae, entre otras.

Existen sobre 1.400 patógenos para el hombre y en más de la mitad su origen está en especies animales, patógenos que se transmiten desde vertebrados (animales) al hombre, que es lo que denominamos zoonosis.

El virus que hoy ha generado la pandemia actual ha sido denominado por la Organización Mundial de la Salud (OMS) 2019-nCoV, el Comité Internacional de Taxonomía de Virus lo denominó SARS-
CoV-2. Se trata de un coronavirus con múltiples mutaciones, que le confieren propiedades de transmisibilidad y virulencia únicas, por lo que se considera un nuevo virus para los humanos. El virus en cuestión pertenece a los betacorona virus. Las proteínas de superficie del virus demuestran que los dos agentes causales de SARS y MERS son semejantes a las de SARS-CoV-2, pero que en ciertas regiones se diferencian.

Los animales que transmiten los coronavirus al hombre son principalmente los murciélagos, huéspedes naturales de esta familia de virus, con una similitud de las secuencias genómicas entre el virus en el hombre y en los murciélagos superior al $85 \%$.

Al día de hoy, 198 países del mundo se encuentran afectados de acuerdo a Johns Hopkins University (JHU), con sobre 510.000 casos confirmados, 22.993 muertes y 120.983 personas ya recuperadas. Recién el 30 de enero del 2020, la Organización Mundial de la Salud (OMS) declaró la emergencia de salud pública global, habiéndose reportado 9.000 casos en 18 países. Dentro de este complejo escenario, afortunadamente hay países que muestran una disminución de casos, como República de Corea y China, sin embargo, países de la Unión Europea continúan con un importante incremento de casos y lo que es peor con una alta letalidad, como ocurre en España e Italia, con cifras de 7,1\% y 9,9\% respectivamente. Estados Unidos, por su parte, inició diagnóstico en etapa muy tardía y hoy se encuentra ante una epidemia con bajo nivel de control y de incierto futuro.

Aunque desde el inicio del recorrido de este virus han transcurrido ya casi tres meses, existen varias dudas sin resolver, tales como ¿cuál es el nivel de infección oligo y/o asintomática y su potencial rol en la transmisión del virus?, ¿la infección en niños ha sido de baja frecuencia e intensidad, por qué?; ¿cuál es el mejor criterio de alta de casos graves de la enfermedad que han requerido ser

(1) Profesora Titular, Universidad de los Andes, Ex Directora del Instituto de Salud Pública, Santiago, Chile. 
hospitalizados por largos días y sometidos a ventilación mecánica. ¿Actualmente se recomienda dos test de PCR negativos separados por 24 horas? ¿Cuál es el rol de los diferentes tipos de test "rápidos" y cuando dispondremos de ellos en Chile?

En Chile el primer caso diagnosticado se notificó el 3 de marzo del 2020 y a la fecha -23 días después- ya tenemos sobre 1.300 casos confirmados y nos encontramos en la fase IV de la pandemia, es decir el virus circula en la comunidad, primordialmente en la Región Metropolitana. Las medidas de prevención ampliamente difundidas por la autoridad de salud son más que necesarias: lavado de manos, limpieza de superficies, distanciamiento entre las personas (OMS ha recomendado dejar de usar el término "social" por sus implicancias más allá de lo solamente físico), diagnóstico masivo y precoz de la enfermedad, aislamiento de los enfermos y cuarentena de todos los contactos de un caso.

Para llegar al anhelado momento de detener esta epidemia, deberemos confiar y obedecer todas las instrucciones y fortalecer una herramienta fundamental, cual es la vigilancia epidemiológica -clínica y de laboratorio- de los casos sospechosos y de los contactos. Hoy habrá que apoyarse en herramientas tecnológicos para que todas las medidas se cumplan, a modo de ejemplo el uso de georreferenciación de los casos y contactos, tener sensores que identifiquen a quienes deben cumplir con la cuarentena, uso de dispositivos que permitan tomar temperatura, plataformas donde se pueda responder encuestas breves conectadas a un centro asistencial desde donde se pueda asistir a esas personas oportunamente. Sin embargo, lo más importante es empoderar a la ciudadanía, haciendo uso de aplicaciones de seguimiento, uso extensivo de métodos de detección temprana de los casos, entregando a la sociedad completa reportes transparentes de la situación epidemiológica y en la colaboración voluntaria de un público bien informado.

La comunicación de riesgo a la comunidad es esencial, constituyendo un Sistema de Comando Unificado y Efectivo, lo que significa que desde la autoridad en salud debe existir un sólo representante como vocero. El comando se encarga de planificar y coordinar todas las acciones y estrategias para el control de la epidemia, canalizando y unificando las estrategias del gobierno, el que incorpora el intersector: Interior, Educación, Trabajo, Transporte, Economía, Hacienda, Desarrollo Social, Defensa y la comunidad/sociedad.

Por último, otro eje importante es la Educación en Salud a la comunidad mediante fuertes campañas de comunicación en terreno, en las calles, donde se vaya explicando las razones de las medidas adoptadas y apoyo psicológico para sostener los largos períodos de encierro.

En el futuro más cercano esperamos con ansias contar con métodos de diagnóstico rápido para cumplir con el diagnóstico precoz (early detection), notificación de los casos sospechosos y confirmados (early notification), aislamiento de los casos confirmados y cuarentena de los contactos (early derivation) y tratamiento temprano (early treatment). Se requiere disponer de tratamientos efectivos en lo posible para etapas precoces y más avanzadas de la infección/ enfermedad, así como vacunas seguras y eficaces (ambas son actualmente anhelos, que requerirán de investigación confiable), usar herramientas como "Big Data”, que permitan compilar y diseminar información epidemiológica para la detección inmediata de los nuevos casos de COVID-19 a través de redes sociales. La "Big Data" apoyará el desarrollo de modelos de infección y predicción, la identificación de la movilidad de la población, conducción de investigación epidemiológica y una trazabilidad más exacta de los contactos. Podrá ser usada para contactar a los pacientes y a la familia, mediante un acompañamiento y así detectar a quienes están padeciendo de ansiedad, de tensiones difíciles de controlar y que a la fecha ha sido poco considerada.

Sin duda nuestra sociedad y nuestro planeta serán distintos después de superar el SARS-CoV-2, con un impacto probablemente más profundo aún que el de la gripe española (influenza) de 1918. Esperemos que como especie saquemos los aprendizajes adecuados 